\title{
Life-style and Dietary Factors Early and Late in Parkinson's Disease
}

\author{
P. Vieregge, C.v. Maravic and H.-J. Friedrich
}

\begin{abstract}
The study investigated features of life-style and dietary habits early and late in life of patients with idiopathic Parkinson's disease (IPD). Seventy-one patients and 103 controls were interviewed personally with a structured questionnaire. Living in villages during primary school time was significantly more frequent among patients, and in the urban environment patients had lived less frequently in larger-sized towns. Mushroom harvesting during childhood was more frequent among patients. No difference between patients and controls was found in childhood water supply, habits of fishing in the countryside or at the seaside, and eating such fish. Actual food preference in patients was greater for almonds and plums, while no difference was found in the actual intake of mushrooms, peanuts, oil-dressed salad, fish and animal offals. The study did not indicate a higher consumption of foods known to harbour heavy metals and pesticides in IPD patients either long before or during the disease. Reduced consumption of foodstuffs rich in vita$\min \mathrm{E}$, as reported previously for premorbid patients, is no longer observed in patients with overt disease.
\end{abstract}

RÉSUMÉ: Facteurs reliés au mode de vie et à la diète au début et tard dans la vie de patients atteints de la maladie de Parkinson. Cette étude a investigué les caractéristiques du mode de vie et les habitudes alimentaires au début et tard dans la vie de patients atteints de la maladie de Parkinson idiopathique (MPI). 71 patients et 103 contrôles ont été interviewés personnellement au moyen d'un questionnaire structuré. La résidence dans un village pendant la période de scolarisation primaire était significativement plus fréquente parmi les patients, et ceux qui vivaient dans un environnement urbain avaient vécu moins fréquemment dans des grandes villes. La récolte de champignons pendant l'enfance était plus fréquente parmi les patients. Il n'existait aucune différence entre les patients et les contrôles quant à l'approvisionnement en eau dans l'enfance, à l'habitude de pêcher en eau douce ou à la mer et à la consommation du produit de ces pêches. Les préférences alimentaires des patients étaient plus grandes pour les amandes et les prunes, alors qu'aucune différence n'a été mise en évidence dans la consommation actuelle de champignons, d'arachides, de salades avec huile, de poissons et d'abats. L'étude n'a pas montré une consommation d'aliments reconnus comme pouvant contenir des métaux lourds ou des pesticides chez les patients atteints de MPI, soit longtemps avant ou pendant la maladie. Une consommation réduite d'aliments riches en vitamine $E$, telle que rapportée précédemment chez les patients en phase prémorbide, n'est observée chez les patients dont la maladie est évidente cliniquement.

Can. J. Neurol. Sci. 1992; 19: 170-173

Interest in environmental agents linked to idiopathic Parkinson's disease (IPD) has arisen from different sources in recent years. Modern prevalence of IPD is greatest in countries where industrialization is longstanding. ' Higher prevalences of IPD, as found epidemiologically in rural populations have been associated with exposure to pesticides due to well water consumption. ${ }^{2 \cdot 4}$ As some pesticides, such as paraquat, are structurally related to MPTP, it was suggested that acute or long-term exposure to such substances may provide a risk factor in developing IPD. ${ }^{1.5}$ Wood pulp or steel alloy industries in both Canada and Sweden have been found located in areas with higher than average IPD prevalence. ${ }^{2,6}$ Unknown consequences of industrialized life style occurring mainly in the rural environment may thus carry a risk for IPD. However, not only risk factors in the rural environment, but also protective factors in an urban setting may be of importance. One such factor, that may behave differently, is diet.

It has been suggested that Parkinsonian patients were less likely to consume nuts, plums, and salad oil or dressing early in life and long before the onset of the disease. It was concluded that less consumption of such foods, which are rich in vitamin $\mathrm{E}$, might result in a reduced antioxidant capacity in the free radical formation processes in the substantia nigra (SN). ${ }^{5.7 .8}$ The following case-control study was undertaken as a pilot study in order to raise new hypotheses on the following issues: 1) Are various early-life features commonly associated with rural environment encountered differently in patients with IPD and controls, when the age range of disease onset in IPD patients is extended to 65 years? 2) Do these features of rural life provide clues, which

From the Klinik für Neurologie (P.V., C.v.M.) und Institut für Medizinische Statistik und Dokumentation (H.-J.F.), Medizinische Universität zu Lübeck, D-2400 Lübeck, Federal Republic of Germany

Received July 25, 1991. Accepted in final form December 23, 1991

Reprint requests to: Dr. P. Vieregge, Klinik für Neurologie, Medizinische Universität zu Lübeck, Ratzeburger Allee 160, D-2400 Lübeck FRG 
kind of rural behaviours may be related to IPD? 3) Are early-life food preferences reported recently ${ }^{5,7}$ also encountered in the present life-style of IPD patients?

One major interest was to enquire about: 1) foodstuffs presently eaten in raw and dressed preparations; 2) those possibly eaten by large samples of people all over the world and 3 ) foodstuffs commonly associated with a rural environment or a potential risk of high heavy metal content. ${ }^{9.10}$

Various species of mushrooms are eaten in many parts of the world. They are easily accessible to many people either by direct harvesting or by marketing. " Mushrooms accumulate both heavy metals (e.g. mercury or cadmium) and pesticides. ${ }^{12,13}$ Mushroom intake was tested by us to be a possible further example of a food agent related to neurologic disease, as has been put forward for the raw seeds of Cycas circinalis in the amyotrophic lateral sclerosis-Parkinson-dementia disease of Guam and the Pacific islands. ${ }^{14}$

\section{MethodS}

\section{a) Patients and Controls}

During 1989 and 1990, 71 patients (41 males, 30 females) with known idiopathic Parkinson's disease (IPD) were investigated. They were consecutive in- or out-patients from the Klinik für Neurologie of the Medizinische Universität zu Lübeck. Diagnostic criteria for IPD were at least two of the following signs: resting tremor, cogwheel rigidity, bradykinesia, impaired postural reflexes and, additionally, a favourable response of motor symptoms to levodopa. All patients were examined by the same neurologist (P.V.). Patients were asked about age of symptom onset, of disease duration, and whether the first symptom was tremor, stiffness of muscles or other. Only patients with symptom onset before the age of 65 were included to avoid diagnostic interferences due to mental impairment of higher age or accompanying disease.

One hundred and three experimentees ( 62 males, 41 females) served as controls. They were matched with the patients for birth age ( \pm 5 years) and for sex. Controls were mostly in- or outpatients of the same clinic and suffered from diseases of the peripheral nervous system (e.g. traumatic nerve lesions) or from neuroorthopedic problems. Three controls were spouses of patients. In general, spouses were not taken as controls to avoid skewing of sex distribution and to exclude common dietary habits in a family, as interest in our study was for prior and actual diet. Control subjects with extrapyramidal and psychiatric diseases and treatment by neuroleptic or antidepressive drugs were excluded. Also excluded were probands - patients and controls, - who were diabetics, or vegetarians, or prior or current alcoholics. Those who employed a special diet for any reason - disease- or non-disease-related - who were of foreign origin (e.g. refugees or working people from Southern Europe) or who had settled from the German Democratic Republic after 1970 were also not considered for the study. Subjects with cognitive impairment due to dementia or medication were excluded. This was tested by asking for the postal code of their present residence, the district town of their birth place or the name of their primary school. All subjects, patients and controls, had their current place of residence no more than 120 kilometers from the coast of either the North or the Baltic Sea, both surrounding the province of Schleswig-Holstein, where the investigation was undertaken.

\section{b) Questionnaire}

Both groups, patients and controls, were asked personally using a fixed questionnaire concerning IPD, senile tremor, or confusional states in the elderly in parents, sibship, and children. Both groups were asked about their place of residence during primary school time (usually 6 th to 10 th year of life; village = below, town $=$ over 5000 inhabitants), and whether drinking water was supplied by wells or by pipelines at that time. Pesticide use was not asked for. Questions regarding mushroom consumption were: Do you like to eat mushrooms? Raw? Canned?

Were mushrooms harvested by yourself alone or with patient's sibs during childhood and youth?

Were the mushrooms that you harvested prepared and eaten by yourself?

Approximate age when first harvesting mushrooms (up to 10; 20; over 20 years)?

Frequency of mushroom harvesting up to 20 years of age (up to $10 ; 20$; over 20 times)?

Were the harvested mushrooms also eaten by sibs?

Simple further questions related to other food items according to the findings of Golbe et al..5.7

Do you like to eat almonds, peanuts, plums, oil-dressed salad, fish in different preparations, animal offals (e.g. liver, kidney, brain, etc.)?

Have you ever in your life caught fish in the countryside or at the seaside more than once and eaten the self-caught and selfprepared fish?

No other food items were asked. In a pretest questionnaire on 15 patients with IPD without age limitation and on 15 controls, a more detailed questionnaire on mushroom species and quantitative measures had not proven useful and was therefore omitted from the main study.

\section{c) Statistical Analysis}

Two-sided significance levels (p-values) were estimated by calculating a Pearson chi-square test corrected for continuity. Several tests were undertaken. As the study was conducted to create raw hypotheses on lifestyle and dietary factors in IPD, Bonferroni correction was not applied, and a significance level of alpha $=0.05$ was chosen.

\section{RESULTS}

Mean age of the 71 patients was $60.0 \pm 9.3$ years (26 to 75 years). Mean age at disease onset was $51.9 \pm 9.8$ years (17-65). Mean age at diagnosis was $53.7 \pm 9.6$ (19-68 years). Mean disease duration was $8.6 \pm 5.6$ years (1-26). Five of the patients gave symptoms at onset other than "tremor" or "muscular stiffness". Out of the resulting 66 patients, 32 had tremor and 34 muscular stiffness as symptom at onset. Six patients had disease onset before 40 years of age.

Mean age of the 103 controls was $63.0 \pm 10.8$ years (19-87 years). There was no statistical difference between mean ages of patients and controls.

There were no differences in the number of first-degree relatives with Parkinsonism or confusional state in old age between patients and controls. Patients indicated significantly more relatives with senile tremor compared to controls $(p \leq 0.01)$.

Living in villages during primary school time was significantly more frequent among patients $(p \leq 0.05)$. This was also 
obvious for small towns, when urban environment was divided into towns below and above 50,000 inhabitants ( $\mathrm{p} \leq 0.05$ ). Patients had harvested mushrooms during childhood and adolescence (up to 20 years) more frequently than controls ( $p \leq 0.01$ ). No difference was found in consumption of these self-harvested mushrooms and age of first self-harvesting.

Patients gave actual food preference more frequently than controls for almonds ( $p \leq 0.05$ ) and for plums ( $p \leq 0.05)$. There was no difference in actual intake of mushrooms, peanuts, oildressed salad, fish, and animal offals. There was no difference in childhood water supply (wells vs. pipes), in habits of fishing in the countryside or at the seaside during their lifetimes and preparing and eating the self-harvested fish.

There were no correlations between age of disease onset, type of the first symptom and either rural or urban childhood life, different types of drinking water supply, mushroom or fish harvesting, or actual food preferences. The results in patients with disease onset below the age of 40 were similar with respect to these items.

\section{Discussion}

The sample of IPD cases taken for the present investigation was typical of the in- and out-patients treated at a movement disorders clinic of a university hospital. Here and in previous studies, a high incidence of tremor in relatives of IPD index cases was observed. ${ }^{15}$ There are, however, frequent misdiagnoses of different tremor types and parkinsonism/IPD especially in higher age groups. ${ }^{16}$ As the present investigation was not primarily focussed on familial extrapyramidal disease, we did not investigate personally the allegedly symptomatic relatives to establish an association between tremor and IPD.

It has been hypothesized that the pathological insult to the substantia nigra occurs or begins at least two or three decades prior to symptom onset, when $80 \%$ of the nigral dopaminergic function is lost. ${ }^{17}$ In recent years, therefore, research on possible risk factors for IPD has focussed on patients with disease onset before age 40 ("young-onset"). A study from Saskatchewan was the first to propose that young-onset IPD patients were born and raised in rural environments and used well water for drinking. ${ }^{4}$ Other case-control studies gave evidence for different environments in IPD patients when compared to controls, also when age of onset was after 40 years. ${ }^{1,18}$ This finding was corroborated in our study for the item "rural life during time of primary school" in IPD patients. Surprisingly, IPD patients were more likely to live in medium sized towns, when urban environment was divided by towns of up to 50,000 inhabitants and over. This result is difficult to explain. One possibility could be that 40 to 50 years ago environmental agents of industrialized life, if they played a significant role in IPD etiology, were not as prevalent in the medium-sized towns of a mostly agricultural region, from which our patients originated. On the other hand, protective factors against the disease may be associated with metropolitan rather than with an urban setting in general.'

In contrast to earlier studies, we did not find differences in water supply facilities during childhood between patients and probands. ${ }^{3.18}$ Also other items related to rural life, like fishing and consumption of self-caught fish during later life, were not different in patients and controls. An earlier study on IPD prevalence with regional differences in Iceland claimed that different fish intake might have contributed to this finding. ${ }^{19}$ Another study from Malaysia did not find different intake of fish food in Parkinsonians; it was, however, focussed on sea-food and did not consider fishes of the countryside. ${ }^{20}$

The reasons for asking about early-life consumption of mushrooms in our study were the same as in the studies of Golbe et al., who, however, did not investigate mushrooms.5.7 The percentage of persons, who had harvested mushrooms during childhood, was higher in the group of patients than in controls, and patients had lived more often in a rural environment during childhood. However, history of previous or actual selfharvesting of mushrooms was not different between the two groups. At present therefore, there is no clear indication, if mushrooms may play a role as an etiologically related dietary factor in IPD.

In the third part of our study, the actual consumption of almonds, peanuts, plums, and oil-dressed salad was examined. Earlier retrospective studies showed those foodstuffs to be consumed less by groups of future IPD patients after their 18th year of life or between marriage and the 40 th year of life. ${ }^{5.7} \mathrm{We}$ found no differences in peanut and oil-dressed salad consumption between patients and controls, but interestingly, patients gave a preference for almonds and plums. There was no correlation between these preferences and age of disease onset. These results do not confirm the findings given by patients for times long before disease onset. ${ }^{5.7}$ Moreover our patients' preference for eating almonds and plums contrasts with a so called "premorbid pattern" of nutrition. ${ }^{5.7}$ In patients with IPD, the consumption of vitamin-E-rich foods is equal to (peanuts, oil-dressed salads) or greater than (almonds, plums) in control subjects: the relevance of this remains open for discussion. The findings show, at least, that IPD patients are no exception to the common experience that dietary habits may change during life. The results show that the role of dietary vitamin $E$ in propagation, acceleration, or retardation of the natural course of IPD during a patients' life is not as simple as previously thought. ${ }^{5.7}$

\section{REFERENCES}

1. Tanner CM. The role of environmental toxins in the etiology of Parkinson's disease. Trends Neurosci 1989; 12: 49-54.

2. Barbeau A, Roy M, Cloutier T, Plasse L, Paris, S. Environmental and genetic factors in the etiology of Parkinson's disease. Adv Neurol 1986; 45: 299-306.

3. Rajput AH, Uitti RJ, Stern W, Laverty W. Early onset Parkinson's in Saskatchewan: environmental considerations for etiology. Can J Neurol Sci 1986; 13: 312-316.

4. Rajput AH, Uitti RJ, Stern W, et al. Geography, drinking water chemistry, pesticides and herbicides and the etiology of Parkinson's disease. Can J Neurol Sci 1987; 14: 414-418.

5. Golbe LI, Farrell TM, Davis PH. Follow-up study of early-life protective and risk factors in Parkinson's disease. Mov Dis 1990; 5: 66-70.

6. Aquilonius SM, Hartvig P. A Swedish county with unexpectedly high utilization of anti-Parkinsonian drugs. Acta Neurol Scand 1986; $74: 379-382$.

7. Golbe LI, Farrell TM, Davis PH. Case-control study of early-life dietary factors in Parkinson's disease. Arch Neurol 1988; 45: 1350-1353.

8. Tanner CM, Cohen JA, Summerville BC, Goetz CG. Vitamin use and Parkinson's disease. Ann Neurol 1988; 23: 182.

9. Berg HW, Diehl JF, Frank H. Rückstände und Verunreinigungen in Lebensmitteln. Darmstadt: Dr. Dietrich Steinkopff, 1987; 7, $12,16$. 
10. Lindner E. Toxikologie der Nahrungsmittel. Stuttgart: Georg Thieme, 1979: 63 .

11. Bötticher F. Pilze und Pilzdauerwaren. In: Acker L, Bergener KG, Diemair W, et al., eds. Handbuch der Lebensmittelchemie, Bd. V, 2. Teil. Berlin: Springer 1986: 507-537.

12. Lorenz H, Kossen MT, Käferstein FK. Blei-, Cadmium- und Quecksilbergehalte in Speisepilzen. Bundesgesundheitsbl 1987; 21: 202-204.

13. Michael E, Henning B. Handbuch für Pilzfreunde. Vol 1. Die wichtigsten und häufigsten Pilze mit besonderer Berücksichtigung der Giftpilze. Stuttgart: Gustav Fischer 1983: 53-54.

14. Spencer PS, Nunn PB, Hugon J. Guam amyotrophic lateral sclerosis-parkinsonism dementia linked to a plant excitant neurotoxin. Science 1987; 237: 517-522.
15. Lang AE. Genetics. In: Koller WC, ed. Handbook of Parkinson's Disease. New York: Marcel Dekker Inc. 1987: 81-97.

16. Martila RJ, Rinne UK. Epidemiology of Parkinson's disease in Finland. Acta Neurol Scand 1976; 53: 81-102.

17. Bernheimer $\mathrm{H}$, Birkmayer $\mathrm{W}$, Hornykiewicz $\mathrm{O}$, Jellinger $\mathrm{K}$, Seitelberger $F$. Brain dopamine and the syndromes of Parkinson and Huntington. J Neurol Sci 1973; 20: 415-455.

18. Koller W, Vetere-Overfield B, Gray C, et al. Environmental risk factors in Parkinson's disease. Neurology 1990; 40: 1218-1221.

19. Gudmundsson KR. A clinical survey of Parkinsonism in Iceland. Acta Neurol Scand 1967; 33: 9-61.

20. Ngim $\mathrm{CH}$, Devathasan G. Epidemiologic study on the association between body burden mercury level and idiopathic Parkinson's disease. Neuroepidemiology 1989; 8: 128-141. 